\title{
Tests for attraction to prey and predator avoidance by chemical cues in spiders of the beech forest floor
}

\author{
Melissa B. Wetter, Bettina Wernisch \& Søren Toft
}

doi: $10.5431 /$ aramit4308

\begin{abstract}
Spiders leave draglines, faeces and other secretions behind when traveling through their microhabitat. The presence of these secretions may unintentionally inform other animals, prey as well as predators, about a recent and possible current predation risk or food availability. For a wolf spider, other spiders including smaller conspecifics, form a substantial part of their prey, and larger wolf spiders, again including conspecifics, are potential predators. We tested two hypotheses: that large wolf spiders may locate patches of potential spider prey through the presence of silk threads and/or other secretions; and that prey spiders may use secretions from large wolf spiders to avoid patches with high predation risk. We used large (subadult or adult) Pardosa saltans to provide predator cues and mixed dwarf spiders or small (juvenile) P. saltans to provide prey cues. Subadult wolf spiders were significantly attracted to litter contaminated by dwarf spiders or small conspecifics after 6 hours but no longer after 24 hours. In contrast, neither dwarf spiders nor small $P$. saltans showed significant avoidance of substrate contaminated by adult $P$. saltans. However, small $P$. saltans showed different activity patterns on the two substrates. The results indicate that wolf spiders are able to increase the efficiency of foraging by searching preferentially in patches with the presence of intraguild prey. The lack of a clear patch selection response of the prey in spite of a modified activity pattern may possibly be associated with the vertical stratification of the beech litter habitat: the reduced volume of spaces in the deeper layers could make downward rather than horizontal movement a fast and safe tactic against a large predator that cannot enter these spaces.
\end{abstract}

Key words: Anti-predatory response, Araneae, cannibalism, IGP, Lycosidae, prey detection

A kairomone is "a chemical that is produced by one organism conveying information to another organism of a different species; it is advantageous to the recipient but detrimental to the producer of the chemical" (RESH \& CARDÉ 2003). Many animals do not leave a single chemical but instead a complex of secretions, and recipients may benefit by using several senses to detect the multitude of simultaneous visual, mechanical or chemical cues (DICKE \& GROSTAL 2001) to get more detailed information about the previous occupant of the patch than can be obtained from a single chemical cue. Spiders leave draglines as witnesses of their locomotory activity, but faeces and other secretions may be released as well. Other animals that are able to decode this information, whether potential prey or predators, may benefit either through avoiding a predator by leaving the patch, or by concentrating their search in patches where prey have recently been active. Silk lines and other secretions thus have "kairomonal function" in the sense of unintentionally

\footnotetext{
Melissa B.WETTER, Bettina WERNISCH, Søren TOFT, Department of Bioscience, Aarhus University, Ny Munkegade 116, DK-8000 Aarhus C, Denmark

Correspondence: soeren.toft@biology.au.dk
}

submitted:25.11.2011, accepted:20.4.2012; online early:25.7.2012 informing other individuals about the level of activity in the patch and the identity of previous occupants. In many predator-prey contexts, especially in the case of spiders, restriction of the kairomone concept to interspecific information transfer is unfortunate. Conspecifics may be as important as prey or predators as any heterospecific animal, and unintentional information may benefit these to the same extent. Finally, many experimental setups (including the one used in this paper) are not designed to identify the exact cue(s) to which the animals respond. Therefore, in this study we analyse to what extent secretions left by spiders are used by other spiders - whether of the same or different species - as sources of information about potential prey and predators.

There is substantial evidence to support the use of silk and/or other secretions as information sources allowing anti-predatory responses in spiders, especially among wolf spiders (DICKE \& GROSTAL 2001, PERSONS et al. 2001, BARNES et al. 2002, PERSONS et al. 2002, PERSONS \& LYNAM 2004). Much less is known about whether spiders can use cues from their prey and thus increase foraging efficiency. A few studies have established that some spiders can detect cues from other spider prey species when foraging (KESSLER \& LAAN 1990, PERSONS \& RYPSTRA 2000), but none 
of these have included a test of whether cannibalistic spiders may similarly utilize cues from individuals of their own species.

Non-web building spiders spend a considerable amount of time in search of prey, and estimates of average capture rates are usually quite low (e.g. NYFFELER \& BENZ 1988). As a result, these spiders are often limited by food in nature (WISE 1993). Their success will be increased if they can search non-randomly by recognizing patches of the habitat that are rich in potential prey while poor in the spider's own predators. The present experiments were intended to gain evidence about the use of silk and/or other secretions for prey detection and predator avoidance among spiders of the beech forest floor. A dominant predator in the habitat is the wolf spider Pardosa saltans Töpfer-Hofmann, 2000, while an assemblage of dwarf spiders as well as small juveniles of $P$. saltans are the most abundant potential intraguild prey. We expected that large $P$. saltans would be attracted to litter contaminated by secretions from the potential intraguild prey, while these should tend to avoid litter contaminated by secretions from large wolf spiders.

\section{Materials and methods}

\section{Spiders}

The wolf spider Pardosa saltans is a common species of deciduous forests in Denmark. Like other Pardosa species, it has a mixed searching and sit-and-wait foraging behaviour, named the "sit-and-move" tactic by SAMU et al. (2003); i.e. they spend most of the time waiting for prey to come to them, but frequently change position. Presumably they end up in patches of high prey availability. Apart from insects, wolf spiders prey on other spiders including individuals of their own genus and species which may form a large proportion of their prey (EDGAR 1969). Cannibalism among wolf spiders is typically committed by a larger spider preying on a smaller, where the latter usually is only half or less of the mass of the former (SAMU et al. 1998). For the design of the experiments we took advantage of the fact that $P$. saltans in Denmark has a biennial life cycle (TOFT 1976, as P. lugubris) with reproduction in late spring. Animals of the second year cohort (i.e. subadults and adults after two overwinterings as juveniles) could therefore be used as predators/ cannibals, and small juveniles of the first year cohort (i.e. after one overwintering) as their conspecific prey. Other litter dwelling dwarf spiders (linyphiids and theridiids) found in the same habitat were used as intraguild prey.
Individuals of $P$. saltans were collected by hand from a beech stand in the mixed forest Lillering Skov west of Århus, Denmark (N 56 8' 32”, E 9 56' 38”, 45 m a.s.1.) during spring months. The cohorts were easily distinguished by their body size even when the large cohort was still not mature (small juveniles: $3-4 \mathrm{~mm}$, subadults: $5-7 \mathrm{~mm}$ ). Litter from the same area was subsequently sifted for dwarf spiders. We used the mixture of different species obtained by sifting. After the experiments they were identified as being from the family Linyphiidae (including - in order of decreasing abundance - Microneta viaria, Diplocephalus picinus, Tenuiphantes tenebricola, Porhomma pallidum, Bathyphantes gracilis, Macrargus rufus, Saloca diceros, Walckenaeria obtusa, W. cucullata, and some unidentified juveniles) and Theridiidae (Robertus lividus). All spiders were kept in individual tubes and stored under cool and moist conditions until the experiments were set up. The spiders used for the predator avoidance experiments were fed intermittently during this period, and they were observed to produce webs both in the tubes and, subsequently, in the experimental petri dishes.

\section{Procedure}

We used the same experimental design, taken from KESSLER \& LAAN (1990), in both the attraction and avoidance experiments. The collected beech litter was washed in boiling water to remove any silk and other secretions it may have contained and laid out for two days to dry thoroughly. The clean and dry beech litter, selected to be of approximately the same size and the same amount, was placed in $9 \mathrm{~cm}$ diameter petri dishes with a small piece of damp cotton in the centre for moisture. The spiders intended to provide the cues were then placed individually in the beech litter dishes and allowed to stay there for 48 hours. Control litter was treated the same way except there was no spider in the petri dishes. In the attractionto-prey series of experiments dwarf spiders or small $P$. saltans were used for pre-treatment of the litter, and large (subadult) $P$. saltans acted as test predators. In the predator-avoidance series of experiments, adult $P$. saltans of both sexes were used for the pre-treatment against which dwarf spiders or small $P$. saltans were tested.

Immediately after the cue-providing spiders were removed from the petri dishes, one dish-full of contaminated litter was transferred to one side of a larger petri dish (14 $\mathrm{cm}$ diameter). This was done with a pair of forceps to prevent human contamination. The 
pile of litter from the small petri dish was transferred as a whole in order to prevent breakage of the silk lines. A similar amount of control litter was placed in the other side of the large petri dish, transferred with forceps and as a whole pile as well. There was a piece of damp cotton in the centre for moisture. We controlled for side biases by facing the contaminated side of half the petri dishes towards one side of the room and the other half towards the other side. In the attraction experiments a series of control dishes with clean litter in both sides were included in order to further rule out any side bias due to unrecognised external factors. The test spider was then placed in an inverted glass tube in the centre of the petri dish between the two groups of litter. It was given one minute to settle there before removing the tube and allowing the spider to move about freely. The position of the large wolf spiders was recorded as being either in the clean litter or in the contaminated litter after 6 hours and again after 24 hours.

The predator-avoidance experiments did not have separate double-control replicates. They were run both with litter as described above and repeated with filter paper instead of litter in the dishes. In the latter series we added an inspection after 2 hours to account for the possibility that predator avoidance might be a faster, but less enduring, response than attraction to prey. All experimental series were replicated 20-30 times. Each spider specimen was used only once. A further supplementary experiment was also performed using filter paper as the substrate and with one half contaminated by an adult female, an adult male or a small juvenile $P$. saltans and using small juvenile $P$. saltans as test animals ( $\mathrm{n}=12$ in each group). For 45 minutes the duration of the activities "sit" and "run" were measured with stop-watches for both the contaminated and the clean filter paper. We expected

Tab. 1: Positions of subadult Pardosa saltans at prescribed inspection times in petri dishes in which one side had clean beech litter and the other had litter contaminated by exposure to potential intraguild (dwarf spiders) or conspecific prey (in the control experiment both sides had clean litter).

\begin{tabular}{l|c|c|c|c}
\hline \multirow{2}{*}{ Prey contaminant } & $\begin{array}{c}\text { Time of } \\
\text { inspection }\end{array}$ & $\begin{array}{c}\text { No. in } \\
\text { contaminated } \\
\text { litter }\end{array}$ & $\begin{array}{c}\text { No. in } \\
\text { clean litter }\end{array}$ & $P^{*}$ \\
\hline \multirow{2}{*}{ Control (clean litter) } & $6 \mathrm{~h}$ & 9 & 11 & 0.748 \\
\cline { 2 - 5 } Dwarf spiders & $24 \mathrm{~h}$ & 10 & 10 & 0.588 \\
\hline \multirow{2}{*}{ Small P. saltans juveniles } & $6 \mathrm{~h}$ & 16 & 4 & $\mathbf{0 . 0 0 6}$ \\
\cline { 2 - 5 } & $24 \mathrm{~h}$ & 13 & 7 & 0.132 \\
\cline { 2 - 5 } & $24 \mathrm{~h}$ & 15 & 5 & $\mathbf{0 . 0 2 1}$ \\
\hline
\end{tabular}

*One-tailed binomial test different responses to adult and juvenile contamination, since small juveniles of the same size as the test spiders would not pose a similar threat as the larger conspecifics. In all experiments observations of spiders that could not unequivocally be assigned to one response, e.g. if the spider was in the spaces between litter types or filter papers, were ignored. The results on patch choice were analysed with the binomial onetailed tests (SIEGEL \& CASTELLAN 1988) and the duration of behaviours by paired $t$-tests (JMP 8.0).

\section{Results}

Attraction to prey cues

Spiders of the control group showed no preference for a particular side of the petri dish at any of the two check times (6 or 24 hours) (Tab. 1). Thus there was no side bias inherent in the experimental set-up. After 6 hours, subadult $P$. saltans were significantly positioned in the litter contaminated by dwarf spiders as well as in litter contaminated by small P. saltans (Tab. 1). This pattern persisted at the 24 hours inspection but it was no longer statistically significant, indicating a weakening effect of the cue that earlier attracted the test spiders.

\section{Avoidance of predator cues}

There was no indication that linyphiids or small $P$. saltans juveniles avoided settling in litter contaminated by a potential spider predator (adult $P$. saltans), whether the predator was a female or a male (Tab. 2). Repeating the same experiment using filter paper instead of litter did not change this result. However, the activity of small juvenile $P$. saltans differed between contaminated and clean filter paper (Fig. 1). Overall, the spiders spent much more time sitting than running (paired $t$-test, $t_{35}=19.3, P<0.0001$ ). The time spent running was significantly lower on contaminated than on clean substrate $\left(t_{35}=3.49, P\right.$ $=0.0013)$. The same was true for sitting, though this was not statistically significant $\left(t_{35}=1.84\right.$, $P=0.075)$. It made no difference whether contamination was by a female, a male or a juvenile (all $P>0.05)$. 
Tab. 2: Positions of test spiders at prescribed inspection times in petri dishes in which one side had clean beech litter and the other had litter contaminated by exposure to potential intraguild (dwarf spiders) or conspecific predator.

\begin{tabular}{|c|c|c|c|c|c|}
\hline $\begin{array}{c}\text { Predator } \\
\text { contaminant }\end{array}$ & $\begin{array}{l}\text { Test spider } \\
\text { (substrate) }\end{array}$ & $\begin{array}{l}\text { Time of } \\
\text { inspection }\end{array}$ & $\begin{array}{c}\# \text { in } \\
\text { contam. litter }\end{array}$ & $\begin{array}{c}\text { \# in } \\
\text { control litter }\end{array}$ & $P^{*}$ \\
\hline \multirow[t]{2}{*}{ P. saltans ad. +} & \multirow{4}{*}{$\begin{array}{l}\text { Dwarf spiders } \\
\text { (litter) }\end{array}$} & $6 \mathrm{~h}$ & 13 & 16 & 0.36 \\
\hline & & $24 \mathrm{~h}$ & 16 & 12 & 0.29 \\
\hline \multirow[t]{2}{*}{ P. saltans ad. ô } & & $6 \mathrm{~h}$ & 16 & 13 & 0.36 \\
\hline & & $24 \mathrm{~h}$ & 15 & 13 & 0.43 \\
\hline \multirow[t]{2}{*}{ P. saltans ad. 우 } & \multirow{4}{*}{$\begin{array}{l}\text { P. saltans juvs } \\
\text { (litter) }\end{array}$} & $6 \mathrm{~h}$ & 10 & 11 & 0.50 \\
\hline & & $24 \mathrm{~h}$ & 9 & 12 & 0.20 \\
\hline \multirow[t]{2}{*}{ P. saltans ad. ${ }^{\hat{O}}$} & & $6 \mathrm{~h}$ & 11 & 12 & 0.66 \\
\hline & & $24 \mathrm{~h}$ & 11 & 11 & 0.58 \\
\hline \multirow[t]{3}{*}{ P. saltans ad. +9} & \multirow{6}{*}{$\begin{array}{l}\text { Dwarf spiders } \\
\text { (filter paper) }\end{array}$} & $2 \mathrm{~h}$ & 16 & 13 & 0.36 \\
\hline & & $6 \mathrm{~h}$ & 15 & 15 & 0.57 \\
\hline & & $24 \mathrm{~h}$ & 13 & 16 & 0.36 \\
\hline \multirow[t]{3}{*}{ P. saltans ad. o $^{-}$} & & $2 \mathrm{~h}$ & 12 & 16 & 0.29 \\
\hline & & $6 \mathrm{~h}$ & 13 & 15 & 0.42 \\
\hline & & $24 \mathrm{~h}$ & 12 & 15 & 0.29 \\
\hline
\end{tabular}

*One-tailed binomial test

\section{Discussion}

Using the same experimental design (though with pine needles instead of beech litter), KESSLER \& LAAN (1990) obtained significant responses indicating attraction of adult females to other conspecific females, and of adult males to adult conspecific females. They also found one linyphiid species that avoided litter contaminated by a potential predator (P. lugubris/saltans in their case too). However, they did not see a significant attraction by wolf spiders to linyphiid-contaminated litter. The present study shows that wolf spiders may choose to settle in a patch which has recently been visited by potential spider prey, irrespective of whether this prey is of a different family or a conspecific. In contrast, we failed to document direct avoidance of a habitat patch infested with predator cues. However, measurements of the activity of small juvenile $P$. saltans when released in the petri dishes indicated a differential response to clean vs. contaminated filter paper. The fact that they spent more time sitting on the clean paper and less time running on the contaminated paper is consistent with an avoidance response, i.e. getting away quickly from a contaminated area and staying in a clean area. Our expectation of a weaker response to contamination from juveniles of the same size as the test spiders compared with contamination from adults was not fulfilled. This may be because cannibalism between same-sized conspecifics can be frequent if the opponents differ in hunger level (PETERSEN et al. 2010). The contaminating spiders left silk lines in the litter and possibly other substances. BARNES et al. (2002) showed that spiders can detect the difference between old and new chemical cues. This was the case in a predator avoidance situation where the cues were of the same type as in our study, i.e. silk and/or other secretions from another spider. Both mechanical and chemical cues may be involved in their detection. In our experiments great care was taken to keep the silk lines intact during manipulations. The weakening of the response after 24 hours may therefore suggest that it is more volatile or easily degradable kairomones associated with the silk or left on the substrate, and not the silk lines as such, that informed the spider about the presence of potential prey. In nature there may be both mechanical and chemical degradation of the silk, though also here chemical degradation of associated chemicals is likely to be faster than physical destruction of silk lines. An alternative explanation for the fading response is the accumulation of the test spider's own silk and secretions during the test period. These would have made it increasingly more difficult to recognize the prey spider's cues as the test progressed. Although this experiment produced evidence that $P$. saltans are able to distinguish between patches which are, or are not, inhabited by intraguild or conspecific 
prey, it is still unknown if they can distinguish between patches with different densities of these prey, and to what extent they can detect patches in the habitat with high densities of their various insect prey. It is also unknown to what extent these abilities help the spiders improve their foraging efficiency compared with random unguided searches.

In summary, Pardosa saltans may use prey cues (silk and/or other secretions) to locate areas with intraguild and/or conspecific prey, but they seem not to directly avoid areas with predator cues. This result is surprising because, a priori, it would be expected that selection for avoiding predators is stronger than selection to obtain a meal. A possible biological explanation may be found in the vertical stratification of deciduous forest litter habitats. Top litter has large spaces, but these become smaller in deeper layers where the old litter is gradually transformed into amorphous humus or mull, and the size of spiders inhabiting these layers decreases accordingly. WAGNER et al. (2003) found the deepest stratum of deciduous forest litter dominated by tiny dictynids and linyphiids and all other families were rare. Thus, small spiders may seek refuge in deeper layers where they are inaccessible to larger spiders. It is even possible that vertical movement may be the safer option, because a horizontal response would only bring the spider to another possibly dangerous patch. The possibility of escaping by vertical movement was not available in the experiments, but has been documented by FOLZ et al. (2006) in a wolf spider from agricultural fields. Due to the structure of this habitat, the escape response here consisted of climbing the vegetation.

\section{Acknowledgements}

ST was supported by grants from the Danish Research Council (FNU) and from the Carlsberg Foundation. We are indebted to two anonymous reviewers for their comments.

\section{References}

BARNES M.C., M.H. PERSONS \& A.L. RYPSTRA (2002): The effect of chemical cue age on antipredator behavior in the wolf spider Pardosa milvina (Araneae: Lycosidae). - Journal of Insect Behavior 15: 269-281 - doi: 10.1023/A:1015493118836

Dicke M. \& P. GRostal (2001): Chemical detection of natural enemies by arthropods: an ecological perspective. - Annual Review of Ecology and Systematics 32: 1-23 - doi: 10.1146/annurev.ecolsys.32.081501.113951

EDGAR W.D. (1969): Prey and predators of the wolf spider Lycosa lugubris. - Journal of Zoology, London 159: 405411 - doi: 10.1111/j.1469-7998.1969.tb03897.x

Folz H.C., S.M. WiLDER, M.H. PERSONS \& A.L. RYPSTRA (2006): Effects of predation risk on vertical habitat use and foraging of Pardosa milvina. - Ethology 112: 1152-1158 - doi: 10.1111/j.1439-0310.2006.01276.x

KESSLER A. \& F.P.J. LAAN (1990): The role of pheromones in the distribution of spiders in the forest litter layer. - Bulletin de la Société européenne d'Arachnologie 1: 172-177 (http://www.european-arachnology.org/ proceedings/12th/Kessler.pdf) 
NYFFELER M. \& G. BENZ (1988): Feeding ecology and predatory importance of wolf spiders (Pardosa spp.) (Araneae, Lycosidae) in winter wheat fields. - Journal of Applied Entomology 106: 123-134 - doi: 10.1111/ j.1439-0418.1988.tb00575.x

Persons M.H. \& E.C. Lynam (2004): Pardosa milvina (Araneae:Lycosidae) spiderling movement in the presence of conspecific and heterospecific silk and excreta. - Journal of Arachnology 32: 341-344 - doi: 10.1636/ S03-18

Persons M.H. \& A.L. Rypstra (2000): Preference for chemical cues associated with recent prey in the wolf spider Hogna helluo (Araneae: Lycosidae). - Ethology 106: 27-35 - doi: 10.1046/j.1439-0310.2000.00496.x

PERSONS M.H., S.E. WALKER \& A.L. RYPSTRA (2002): Fitness costs and benefits of antipredator behavior mediated by chemotactile cues in the wolf spider Pardosa milvina (Araneae: Lycosidae). - Behavioral Ecology 13:386-392 - doi: 10.1093/beheco/13.3.386

Persons M.H., S.E. WALKer, A.L. Rypstra \& S.D. MARSHALL (2001): Wolf spider predator avoidance tactics and survival in the presence of diet-associated predator cues. - Animal Behaviour 61: 43-51 - doi: 10.1006/anbe.2000.1594
Petersen A., K.T. Nielsen, C.B. Christensen \& S. TOFT (2010): The advantage of starving: success in cannibalistic encounters among wolf spiders. - Behavioral Ecology 21: 1112-1117 - doi: 10.1093/beeco/arq119

RESH V.H. \& R.T. CARDÉ (2003): Encyclopedia of insects. Academic Press, Amsterdam. 1266 pp.

SAMU F., A. SZIRÁNYI \& B. KISS (2003): Foraging in agricultural fields: local 'sit-and-move' strategy scales up to risk-averse habitat use in a wolf spider. - Animal Behaviour 66: 939-947 - doi: 10.1006/anbe.2003.2265

SAMU F., S. TOFT \& B. KISS (1999): Factors influencing cannibalism in the wolf spider Pardosa agrestis (Araneae, Lycosidae). - Behavioural Ecology and Sociobiology 45: 349-354 - doi: 10.1007/s002650050570

Siegel S. \& N.J. CASTELLAN Jr. (1988): Nonparametric statistics for the behavioral sciences. 2. Ed. McGrawHill, New York. 399 pp.

TOFT S. (1976): Life-histories of spiders in a Danish beechwood. - Natura Jutlandica 19: 5-40

Wagner J.D., S. TofT \& D.H. Wise (2003): Spatial stratification in litter depth by forest-floor spiders. - Journal of Arachnology 31: 28-39 - doi: 10.1636/0161-8202(2003)031[0028:SSILDB]2.0.CO;2

WiSE D.H. (1993): Spiders in Ecological Webs. Cambridge University Press, Cambridge. 328 pp. 